\title{
Effect of air gap membrane distillation parameters on the removal of fluoride from synthetic water
}

\author{
Osamah Naji ${ }^{\mathrm{a}, \boldsymbol{*}}$, Les Bowtell ${ }^{\mathrm{a}}$, Raed A Al-juboori ${ }^{\mathrm{a}}$, Vasantha Aravinthan, \\ Noreddine Ghaffour ${ }^{\mathrm{b}}$ \\ ${ }^{a}$ Faculty of Health, Engineering and Sciences, University of Southern Queensland, Toowoomba, 4350 QLD, Australia, \\ Tel.+61423648500, email: Osamah.Naji@usq.edu.au, osama.8814@yahoo.com (O.Naji), Tel.+61746311482, \\ email: Les.Bowtell@usq.edu.au (L.Bowtell),Tel.+61 74631 1913, email:RaedAhmed.Mahmood@usq.edu.au (R.A.Al-juboori), \\ Tel.+61 74631 2299, email: Vasanthadevi.Aravinthan@usq.edu.au (V. Aravinthan) \\ ${ }^{b}$ King Abdullah University of Science and Technology (KAUST), Water Desalination and Reuse Center (WDRC), Biological and \\ Environmental Science and Engineering (BESE), 23955-6900 Thuwal, Saudi Arabia, Tel. +966-128082180, \\ email: noreddine.ghaffour@kaust.edu.sa (N. Ghaffour)
}

Received 18 January 2018; Accepted 19 June 2018

\begin{abstract}
A B S T R A C T
As freshly available water around the world becomes scarcer, schemes to reuse and rectify contaminated water sources are becoming a necessity. The implementation of conventional treatment processes increases stress on existing infrastructure resources, requiring significant quantities of energy and/or chemicals, including pre-treatment processes and ongoing maintenance. An unconventional alternative to these processes is air-gap membrane distillation (AGMD), an emerging technology delivering excellent rejection of contaminants over a broad range of operating conditions. While showing great promise, the size of membrane distillation systems in existing literature is not readily scaled to industrial levels. In this paper, we present the results of our research in terms of permeate quality, rejection efficiency and scalability of a large laboratory scale AGMD system, with effective area of approximately 25 times larger than those presented in previous studies. This study found a large discrepancy in flux production when compared with small scale results, with experimental data analysed using normality and residual analysis tests. Statistical analysis of the AGMD process data provides insight into the key driving forces and interactions of feedwater temperature, concentration and flowrate on flux production. Results showed excellent rejection of contaminants (>98\%) along with some fouling evident after approximately $25 \mathrm{~h}$ of operation.
\end{abstract}

Keywords: AGMD; Fouling; Fluoride removal; Decontamination; Desalination

\section{Introduction}

Surface water supplies suitable for fresh water usage have steadily declined due to increases in population, industry and agriculture stressors. Globally more populations are becoming increasingly dependent on groundwater resources for domestic and agricultural purposes. This is especially true in inland areas, where seawater desalination is not a viable option. Groundwater is often available

*Corresponding author. in suitable quantities, however the fluoride levels are unfortunately well above safe drinking limits. According to the World Health Organization (WHO), the maximum permissible safe limit for fluoride in drinking water is $1.5 \mathrm{mg} / \mathrm{L}$ [1].

Fluoride is a naturally occurring highly reactive metallic element found in groundwater. The removal of excess fluoride is necessary to protect both public health and the environment. Fluoride can find its' way into water sources through various pathways stemming from the food industry, pharmaceuticals, cosmetics, semiconductors, ceram- 
ics, electroplating, fertilizer, coal-fired power plants and from naturally sources $[1,2]$. Small amounts of fluoride are useful for the mineralization of bones and teeth [2]. Excess fluoride can result in dental and skeletal fluorosis and may also cause cancer, neurological, muscular, urinary tract and gastrointestinal problems along with lesions of the thyroid $[3,4]$.

Currently available technologies for the removal of fluoride are based on physical and chemical mechanisms. The techniques include: Coagulation with lime, alum, ferric hydroxide, ferric sulphate, sodium sulphate followed by flocculation; sedimentation and filtration; adsorption on activated carbon; ion exchange and reverse osmosis $[3,4]$. These technologies have the following fluoride contaminant removal efficiencies: adsorption (80-90\%), coagulation/filtration followed by lime softening (18-33\%); ion exchange (90-95\%); and reverse osmosis (90-95\%) [3]. Although the above-mentioned processes are efficient in treating a variety of affected waters, they require significant quantities of chemicals and energy to treat brackish waters contaminated with fluoride. These technologies are able to remove a high proportion of fluoride, but they have some inherent limitations such as high energy consumption for processes such as reverse osmosis [4] and high equipment capital cost and required chemicals [5]. Other processes need pre-treatment to be effective, such as ion exchange [6]. By comparison, membrane distillation (MD) has several economic and environmental advantages by working at relatively low temperatures and pressures compared to traditional desalination processes like reverse osmosis and similar treatments. This allows MD to have lower energy requirements and the inherent benefit of requiring fewer chemicals or pre-treatment processes [7]. Another economic advantage of MD's low operating pressure is the reduced maintenance requirement, as mechanical damage to membranes is significantly reduced compared to conventional techniques [8].

MD is a non-conventional technology that may be a feasible alternative to remove contaminants from water such as fluoride. Limited research has been conducted on the feasibility of MD technology to remove fluoride and although what has previously been done was on a very small scale [9-11]. Fluoride removal on a larger scale has not been reported to our knowledge.

The MD process has four typical configurations: direct contact MD (DCMD); sweeping gas MD (SGMD); vacuum MD (VMD) and air gap MD (AGMD). DCMD, SGMD and VMD have several disadvantages, namely high heat transfer, running costs and higher energy consumption, respectively. AGMD is the configuration that has lowest heat transfer requirement as a result of the air gap between the membrane and condensation surfaces. It also has better internal heat recovery, hence lower energy requirement, which makes it our first choice for a pilot plant [12].

The main objective of this study is to investigate the feasibility of the MD process for use in the large-scale treatment of fluoride contaminated water sources, with focus on the effects of feedwater concentration, temperature, flowrate and membrane effective area on flux produced.

The influence of the membrane effective area on the productivity of flux was compared to previous studies to gauge the possibility of scaling up MD. Here, we present the results of the fluoride removal efficiencies using an AGMD process. Thorough statistical analyses of data was applied to gain conclusive insights into the rate of flux produced for a range of concentration, temperature and flowrates of both feedwater and coolant.

\section{Material and methods}

\subsection{Sample preparation}

Synthetic water samples with a range of different contaminant concentrations were prepared using analytical grade sodium fluoride and subsequently used as the feedwater solution. Three different masses of sodium fluoride were prepared in $33 \mathrm{~L}$ of distilled water to achieve fluoride concentrations of lower, equal to and higher than those fluoride concentrations found naturally in groundwater from South East Queensland, Australia, corresponding to 6.6 $\mathrm{mg} / \mathrm{L}, 12.2 \mathrm{mg} / \mathrm{L}$ and $15.4 \mathrm{mg} / \mathrm{L}$, respectively. After preparation, the samples were added to the feed tank of the MD system to perform the experiments.

\subsection{Experimental setup}

A schematic representation of the air gap MD (AGMD) setup is shown in Fig. 1. The experimental setup contains two $33 \mathrm{~L}$ capacity, thermally insulated vessels, hot and cold, representing feedwater and coolant, respectively. Water flows from the feed and coolant tanks into the membrane module $12 \mathrm{~mm}$ polyurethane hoses. These hoses are covered with pipe insulation to reduce system heat losses. Two rotameters (Variable area flow meter type 335, 4-20 mA output, 0-500 $\mathrm{L} / \mathrm{h}$, supplied by Georg Fischer) measured the fluid flows from the two pumps (submersible Model: 24 Volt DC-2.5 Amp, $4 \mathrm{~L} / \mathrm{min}$ ). Two centrifugal pumps are used to individually circulate both the hot feed water and cold permeate in a batch mode operation. The AGMD system was machined from aluminium material with stainless steel fittings. Seven industrial style temperature sensors (RTD Sensor - Pt100 type with Pot Seal) have been connected to the system (four in various locations on the feed side and three on the coolant side). Differential pressure transducers (Wika, type DP250, 0-250 mbar, 4-20 $\mathrm{mA} \mathrm{o} / \mathrm{p}$ ) have also been connected to the feed inlet and outlet sides in order to monitor membrane conditions. In addition, two conductivity sensors (Microchem Conductivity Transmitter supplied by TPS) have been used in this study to measure the conductivity in the feedwater and permeate tanks (high range 1,999 $\mu \mathrm{S} / \mathrm{cm}$ and low range $19.99 \mu \mathrm{S} / \mathrm{cm}$, respectively). An electronic balance with serial interface was used to record the AGMD permeate. All sensors were connected to a SCADA system for data logging and control purposes with local HMI.

To evaluate temperate effects, AGMD feed water at temperatures of $50^{\circ} \mathrm{C}, 60^{\circ} \mathrm{C}$ and $70^{\circ} \mathrm{C}$ were tested while coolant temperature was kept at a constant $20^{\circ} \mathrm{C}$. Feed and coolant systems were continuously heated and cooled, respectively to maintain a homogeneous solution. In order to view flow rate effects, three different feed flow rates have been used: $50 \mathrm{~L} / \mathrm{h}, 100 \mathrm{~L} / \mathrm{h}$ and $150 \mathrm{~L} / \mathrm{h}$, whilst the permeate flow rate was kept constant at $200 \mathrm{~L} / \mathrm{h}$. The inlet and outlet temperatures difference of both the feed and coolant sides was no more than $2^{\circ} \mathrm{C}$ throughout the experiments. 


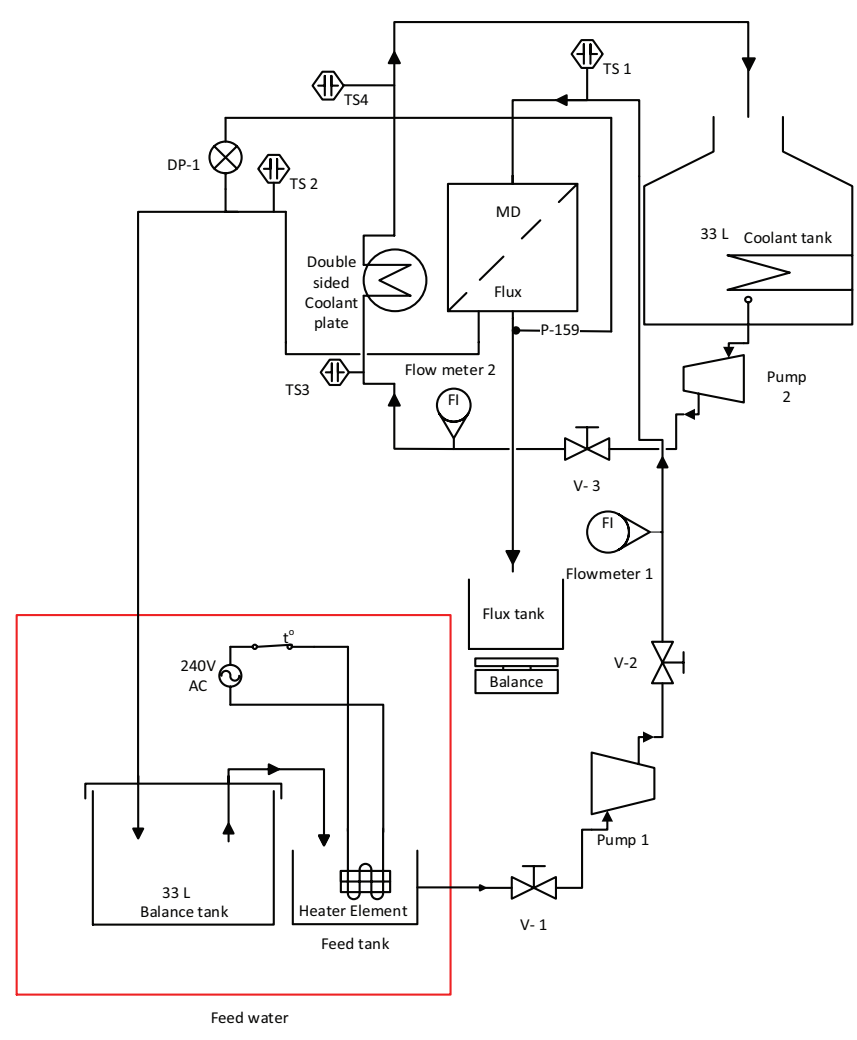

\begin{tabular}{|c|c|}
\hline Item & Description \\
\hline Pump 1 & $\begin{array}{l}\text { Submersible Model: LVMI3I } \\
24 \text { Volt DC-2.5 Amp flow rate } 4 \mathrm{~L} / \mathrm{min}\end{array}$ \\
\hline Pump 2 & $\begin{array}{l}\text { Submersible Model: LVMI3I } \\
24 \text { Volt DC- } 2.5 \text { Amp flow rate } 4 \mathrm{~L} / \mathrm{min}\end{array}$ \\
\hline V1 & $\begin{array}{l}\text { Manual valve, control on the } \\
\text { flow rate on/off heat side }\end{array}$ \\
\hline V2 & $\begin{array}{l}\text { Manual valve, control } \\
\text { on the flow rate, heat side }\end{array}$ \\
\hline v3 & $\begin{array}{l}\text { Manual valve, control on } \\
\text { the flow rate, coolant side }\end{array}$ \\
\hline $\begin{array}{l}\text { Flow } \\
\text { meter } \\
1,2\end{array}$ & $\begin{array}{c}\text { Variable area flow meter type } 335 \\
\text { range } 50-500 \mathrm{~L} / \mathrm{hr}\end{array}$ \\
\hline TS & $\begin{array}{l}\text { RTD Sensor -Pt100 with Pot Seal, } \\
\text { Operating range: }-75^{\circ} \mathrm{C} \text { to } \\
+350^{\circ} \mathrm{C}, 3 \mathrm{~mm} \text { dia } \times 100 \mathrm{~mm} \text { long }\end{array}$ \\
\hline DP-1 & $\begin{array}{l}\text { Wika, Differential pressure } \\
\text { transmitter, Model: DP- } 10 \\
\text { Range: } 0-250 \mathrm{mbar}\end{array}$ \\
\hline Chiller & Model: RC1, Volt: $240 \mathrm{~V} / 50 \mathrm{~Hz}$, Range: $0-30^{\circ} \mathrm{C}$ \\
\hline Heater & Range $0-90^{\circ} \mathrm{C}$ \\
\hline Ec-1 & $\begin{array}{l}0 \text { to } 1 \mathrm{VDC} \text { or } 0 \text { to } 5 \mathrm{~V} \mathrm{DC} \text { Outputs, } \\
\mathrm{k}=1.0 \text { Sensor....0 to } 19.99 \mathrm{uS} / \mathrm{cm}\end{array}$ \\
\hline Ec-2 & $\begin{array}{l}0 \text { to } 1 \mathrm{VDC} \text { or } 0 \text { to } 5 \mathrm{~V} \mathrm{DC} \text { Outputs, } \\
\mathrm{k}=0.1 \text { Sensor....0 to } 19.99 \mathrm{uS} / \mathrm{cm}\end{array}$ \\
\hline Ion $\mathrm{Fl}$ & 0.02 to $19,000 \mathrm{mg} / \mathrm{L} \mathrm{F}-,-0$ to $60{ }^{\circ} \mathrm{C}$ ( 32 to $140{ }^{\circ} \mathrm{F}$ \\
\hline
\end{tabular}

Fig. 1. Schematic representation of the AGMD setup.

The MD module consists of two thermal elements (feed and permeate) machined from aluminium, connected to a membrane module which made of PTFE or similar material. While in practice for large scale MD the heating and cooling sources would make use of waste or naturally occurring heat and cooling sources, we supplied these artificially in the laboratory to allow for a full range of adjustments. The feedwater compartment is connected to a heating system and was maintained at an elevated temperature, while the permeate compartment was connected to a refrigerated cooling system and maintained at a steady cooler temperature to maintain the temperature difference. The hydrophobic membrane was placed between the two compartments and it is able to make direct contact with the heated feedwater side while maintaining an air gap between the membrane and cooled permeate side.

\subsection{Membrane characterization}

In this study, two commercially available membranes, PTFE laminated on typar 3161L spunbond polypropylene and $\mathrm{N}_{20}$ membranes were supplied by Donaldson Filtration solutions. The specification of the membranes used are detailed in Table 1 . The dimensions of the membrane cell channel was $(\mathrm{L} \times \mathrm{W} \times \mathrm{H} 84 \mathrm{~cm} \times 10 \mathrm{~cm} \times 48 \mathrm{~cm})$. A membrane sheet was installed on each side of the cassette allowing feedwater to flow in between the two flat membrane sheets.

\subsection{Fluoride removal measurement}

Fluoride removal effectiveness was measured by using an ion selective electrode (ISE 121560, supplied by TPS) with fluoride ion measurement range of $0.02 \mathrm{mg} / \mathrm{L}$ to 19,000 $\mathrm{mg} / \mathrm{L}$ and an accuracy of $+/-3 \mathrm{mV}$ at $25^{\circ} \mathrm{C}$. The fluoride ion sensor was installed in the inlet pipe of the permeate tank to allow online measurement.

\subsection{Statistical analyses}

Minitab software version 17 (Minitab Inc., PA, USA) was used in to measure the normality of experimental errors, interaction of operating parameters, and provide surface and contour plot interpretations of results. The nominal operating parameters are fluoride concentration, feed temperature and feed flowrate. These factors have the major contributing effects on the resultant permeate flux. Three factors have been assessed in this study, feed temperature and fluoride concentration, temperature and feed flowrate and fluoride concentration and feed flowrate. The response of the permeate flux for each of these scenarios was clearly observed. It is important to note here that only brief statistical analyses were applied in this study to determine the significance of main and interactive effects on responses. This included studying the normality of the obtained data and producing surface plot figures for responses with the various combinations of factors' effects. 
Table 1

Characteristics of $\mathrm{D}_{\text {on }}$ and $\mathrm{N}_{20}$ membranes supplied by Donaldson Filtration solutions

\begin{tabular}{lll}
\hline Specification & $\mathrm{D}_{\text {on }}$ membrane & $\mathrm{N}_{20}$ membrane \\
\hline Material & PTFE & PVDF \\
Support & $\begin{array}{l}\text { Laminated on typar 3161L } \\
\text { spunbond polypropylene }\end{array}$ & Without \\
& 0.3 & 0.3 \\
Pore size $(\mu \mathrm{m})$ & 254 & 154 \\
Thickness $(\mu \mathrm{m})$ & 75 & 80 \\
Porosity $(\%)$ & $48 \mathrm{~cm} \times 84 \mathrm{~cm}$ & $48 \mathrm{~cm} \times 84 \mathrm{~cm}$ \\
Effective area & 114 & 85 \\
Contact angle $\left(^{\circ}\right)$ & 114
\end{tabular}

\section{Results and discussion}

\subsection{Effect of feed temperature}

Fig. 2 shows the effect of feed temperature ranging from $50^{\circ} \mathrm{C}$ to $70^{\circ} \mathrm{C}$ on the permeate flux using $\mathrm{D}_{\text {on }}$ and $\mathrm{N}_{20}$ membranes. The feed water temperature decreased by $2{ }^{\circ} \mathrm{C}$ between the inlet and outlet compartments of the AGMD system. As expected, an increase in feed water temperature resulted in an increase in permeate flux for both membranes tested. Feed water inlet temperature plays an important role in the AGMD process due to its' impact on the temperature difference between both sides of the membrane, i.e. increased trans-membrane vapour pressure leading to a corresponding net increase of in driving force.

The permeate flux transfer of the $\mathrm{N}_{20}$ membrane was slightly higher than that of the $\mathrm{D}_{\text {on }}$ Membrane. However, these fluxes are $50 \%$ lower than what has been previously reported in small-scale studies $[15,16]$. There are several proposed reasons behind the lower than expected flux obtained in our study. Firstly because of the larger effective area of the membrane used $(48 \mathrm{~cm} \times 82 \mathrm{~cm}$ for each of 2 sides in a cassette), around 8 times larger than the membrane used by [12]. There was more heat transfer loss through the membrane surface creating a much lower transmembrane temperature difference and therefore lower flux. Moreover, the pore size of the membranes used in this study is $(0.3 \mu \mathrm{m})$ smaller than those in previous studies $(.45 \mu \mathrm{m})$, there was also logical reason for the lower flux output as increasing the pore size results in an increase of the water flux across the membrane [12]. The membranes used in this study also have a support layer which might be another reason for the lower than expected flux, the use of a support layer has been shown to decrease flux [12]. Increasing the effective area of the membrane consumes higher energy due to the resulting heat transfer. It should also be noted that in a larger system a higher feed flow is required to achieve the same flux level because of the longer residence time of the feed water. The main reason behind the lower permeate flux of the $D_{\text {on }}$ membrane compared to the $\mathrm{N}_{20}$ membrane is that it has a higher thickness of $254 \mu \mathrm{m}$ compared to $154 \mu \mathrm{m}$ of the $\mathrm{N}_{20}$ as well as having a lower porosity of $5 \%$ compared to $80 \%$ of the $\mathrm{N}_{20}$. PTFE was selected in this study as a model membrane due to low cost and ready availability. By comparison with smaller systems, this longer residence time creates a lower transmembrane vapour pressure and hence, lower

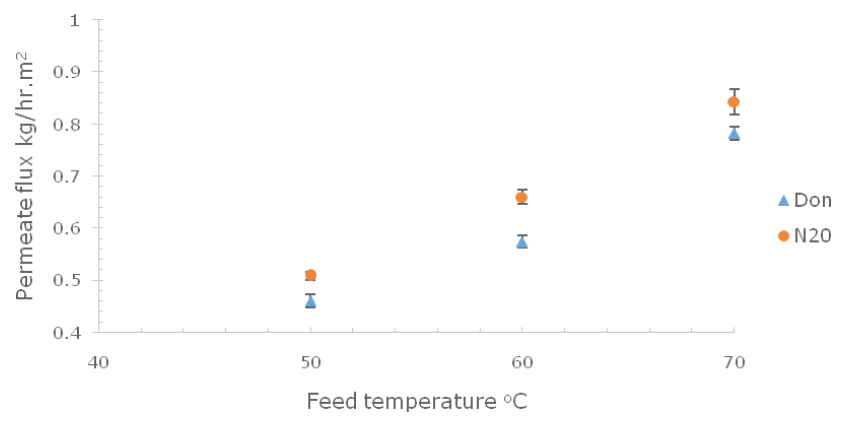

Fig. 2. Effect of feed temperature on permeate flux, $\mathrm{D}_{\text {on }}$ and $\mathrm{N}_{20}$ membranes. $\mathrm{F}^{-}=6.6 \mathrm{mg} / \mathrm{L}$, feed flow $=150 \mathrm{~L} / \mathrm{h}$, inlet coolant temperature $=20^{\circ} \mathrm{C}$.

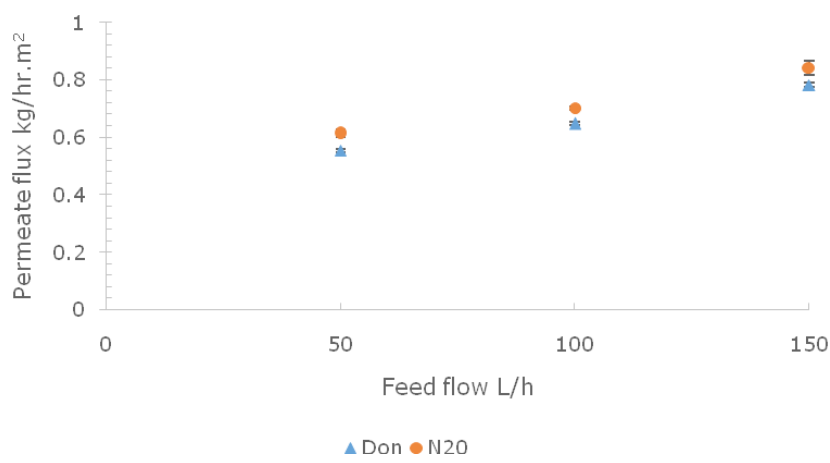

Fig. 3. Effect of feed flow rate on the permeate flux using $D_{\text {on }}$ and $\mathrm{N}_{20}$ membranes. $\mathrm{F}^{-}=6.6 \mathrm{mg} / \mathrm{L}$, inlet feed temp $=70^{\circ} \mathrm{C}$, inlet coolant temp $=20^{\circ} \mathrm{C}$.

flux per unit area is obtained [13]. The relatively low permeate flux per unit area of $0.5 \mathrm{~kg} / \mathrm{h} \cdot \mathrm{m}^{2}$ obtained using the large scale modules ( 2 sides of $48 \mathrm{~cm} \times 82 \mathrm{~cm}$ in a cassette design) compared to the optimistic high fluxes obtained using labscale modules is one of the major reasons for delaying the commercialization of the MD process.

\subsection{Effect of feed flow}

Fig. 3 shows the effects of three levels of feed flow rate of $50 \mathrm{~L} / \mathrm{h}, 100 \mathrm{~L} / \mathrm{h}$ and $150 \mathrm{~L} / \mathrm{h}$ on the permeate flux for $\mathrm{D}_{\text {on }}$ and $\mathrm{N}_{20}$ membranes. It appears that a significant increase of feed flow rate from $50 \mathrm{~L} / \mathrm{h}$ to $150 \mathrm{~L} / \mathrm{h}$ results in only a $33 \%$ increase in the permeate flux, a lesser effect than those presented in other studies [14]. This is most likely due to the large membrane surface area used in our investigation leading to higher residence time and small $\Delta \mathrm{T}$, as discussed previously. The linear relationship between the trans-membrane flux and feed flow up to a certain limit using similar modules [14]. Increasing the feed flow rate leads to a reduced temperature and concentration difference between the feed bulk stream and membrane surface (TP and CP). This is a result of the increasing heat transfer coefficient in the boundary layer [10].

\subsection{Effect of fluoride concentration and rejection}

Fig. 4 shows the effect of fluoride concentration (6.6 $\mathrm{mg} / \mathrm{L}, 12.2 \mathrm{mg} / \mathrm{L}$ and $15.4 \mathrm{mg} / \mathrm{L}$ ) on fluoride rejection and 


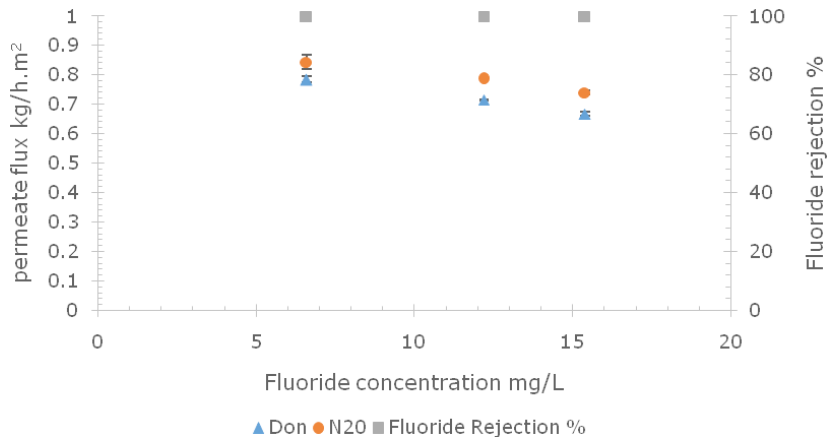

Fig. 4. Effect of fluoride concentration on the permeate flux and fluoride rejection using $\mathrm{D}_{\text {on }}$ and $\mathrm{N}_{20}$ membranes. Feed flow rate $150 \mathrm{~L} / \mathrm{h}$, inlet feed Temp $=70^{\circ} \mathrm{C}$, inlet coolant temp $=20^{\circ} \mathrm{C}$.

permeate flux production for $\mathrm{D}_{\text {on }}$ and $\mathrm{N}_{20}$ membranes. It is clearly shown that the descending gradient of the permeate flux is more severe than the descending trend of the concentration for both $\mathrm{D}_{\text {on }}$ and $\mathrm{N}_{20}$ membranes. Several authors, e.g. Gryta [15], found that the flux decreases were due to the increased salt concentration present in the feed side. Increasing the fluoride concentration in the feed water leads to an increased fouling layer on the membrane surface, which can then cause a decrease in the mass transport through membrane pores. This decrease is largely due to the high fluoride concentration in the feed solution leading to membrane pore blockage [16]. Membranes with 0.3 $\mu \mathrm{m}$ pore size used in this study result in a high rejection of fluoride, but the fouling layer can form more quickly than membranes with larger pore sizes and this is an additional reason for low flux production rates. There are several factors that can affect the flux with increased feed concentration, such as concentration and temperature polarization on the membrane surface [17]. Increasing the feed concentration also results in a corresponding decrease in vapour pressure on the membrane [12].

The increased fluoride concentration in the feed water showed no effect on the rejection rate of fluoride for either membrane, with the rejection of fluoride stable around $99.98 \%$, for both membranes over all of the different operating conditions. This result might be due to the fact that permeate water concentration increases with feed water concentration. This finding is in agreement with results reported by [10] who investigated the removal of fluoride from groundwater using DCMD with a PVDF membrane. The advantage of using MD is flux production with high rejection of contaminants, because of the selective mass transfer of water vapour across the MD membrane. Other advantages of this process are the low electrical and thermal energy required during operation when compared to other thermal processes [18]. Another economic advantage in AGMD's favour is less damage of the membrane than conventional high-pressure techniques [8] and no requirement for chemicals or pre-treatment [7].

\subsection{Scalability}

Fig. 5 shows the effect of membrane effective area $\left(0.4032 \mathrm{~m}^{2}\right)$ on the permeate flux in this study compared to other studies using smaller effective areas of $0.0032 \mathrm{~m}^{2}$

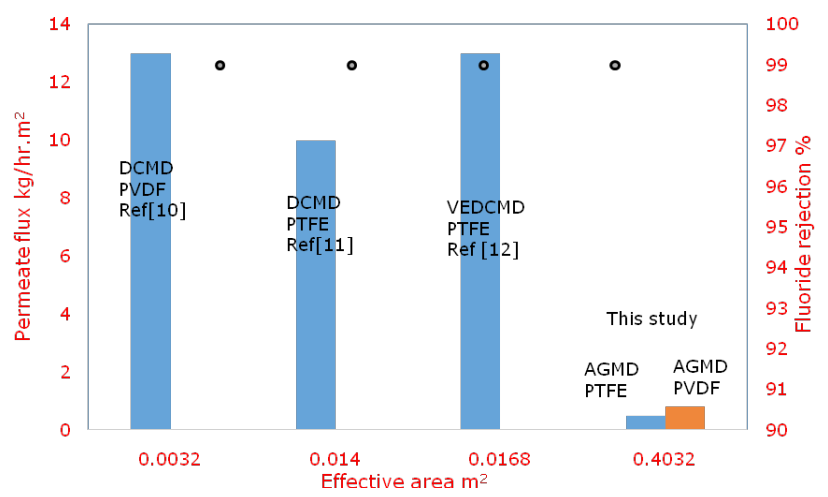

Fig. 5. Effect of membrane effective area and other properties on permeate flux.

[9], $0.014 \mathrm{~m}^{2}$ [10] and $0.0168 \mathrm{~m}^{2}$ [11] at a feed temperature of $60^{\circ} \mathrm{C}$. The removal of fluoride in all previous studies, including in our own studyis $99.9 \%$. However, since all other studies have used the DCMD module configuration where produced water vapor is mixed with the coolant (dilution effect), we conducted our study using AGMD module (collection of pure water vapor) under similar operating conditions and membranes for a better accuracy. In addition, it is important to mention that despite the very low flux obtained in our study due to the very large membrane surface area and module configuration used (see discussion in previous sections) compared to the other studies, the fluoride removal rate was very high and stable (Fig. 5). The flux production rate decreases with an increase in the membrane effective area. Increasing the effective area leads to an increase in heat loss, which resulted in a decreased driving force, especially from the feed side of the AGMD module. Increasing the effective area from $0.0032 \mathrm{~m}^{2}$ to $0.014 \mathrm{~m}^{2}$ resulted in a permeate flux decrease from $13 \mathrm{~kg} / \mathrm{h} \cdot \mathrm{m}^{2}$ to $10 \mathrm{~kg} / \mathrm{h} \cdot \mathrm{m}^{2}$. By comparison, the flux achieved with an effective area of $0.0168 \mathrm{~m}^{2}$ was 13 $\mathrm{kg} / \mathrm{h} \cdot \mathrm{m}^{2}$, which initially appears to go against this trend, however this result used vacuum (VEDCMD) to enhance the flux production. This implies that the flux without vacuum would be considerably lower than $10 \mathrm{~kg} / \mathrm{h} \cdot \mathrm{m}^{2}$ as previously predicted. In this study the effective area is 24 times larger than the area of membrane used by [11] which results in more heat loss through the membrane surface and much lower trans-membrane temperature difference, hence producing less flux [13]. As previously discussed there are several other reasons behind these lower flux production rates such as membrane material, pore size, porosity, and thickness. In this study, the PTFE membrane also has a high thermal conductivity, which results in correspondingly lower flux production rate. Membrane materials with a high thermal conductivity show a lower thermal resistance, which means an increase in the heat transfer through the membrane leading to a decrease in the water vapour on the feed side [19]. Increased pore size of the membrane also leads to increased water flux, however the thickness of the membrane has little observed effect on the permeate flux production [12]. All of the above reasons have minor effects on the permeate flux while the largest effect can be attributed to the large effective area that has been used in this study. According to our results, the dif- 
ference in permeate flux between both membranes is 6\% which is very low compared with the lower flux that has been achieved with our large AGMD module. This confirms that the lower permeate flux obtained in this study is the result of the large effective area of the membrane, which highlights the challenge in scaling up of this process. The large variation of flux results using different module sizes led us to perform normality tests, residual analysis and diagnostic statistics using the obtained experimental data to better understand our results.

\subsection{Normality tests and residual analysis of the experimental data}

It is important to check the normality of the experimental errors for fluoride removal data with both $\mathrm{D}_{\text {on }}$ and $\mathrm{N}_{20}$ membranes through a number of diagnostic tests prior to commencing any statistical analysis on the experimental data to ensure the repeatability of the observations [20]. If the errors are normally distributed, further statistical analysis can be conducted on the experimental data with no additional treatment required [21]. Fig. 6 shows the normal probability plot for both $\mathrm{D}_{\text {on }}(\mathrm{A})$ and $\mathrm{N}_{20}(\mathrm{~B})$ membranes. It is clear from these figures that the errors are normally distributed, illustrated by the residual points being very close to the fitted regression line [22]. The residuals frequency of occurrence being almost bell-shaped, in Figs. $6 \mathrm{c}$ and $6 \mathrm{~d}$, provides additional evidence for the resulting normal distribution of experimental errors [23].

It is also clear that the order in which the experiments were conducted had no effect on the distribution of errors as illustrated by the random variation of the residuals around zero in Figs. 7a and $7 b$ [24,25]. Further diagnostic statistical tests were conducted on the residuals of fluoride removal using both $\mathrm{D}_{\text {on }}$ and $\mathrm{N}_{20}$ membranes data to explore time-related effects on error distribution and to verify the random distribution of the errors throughout the experiments. The external effects such as experimenter performance and conditions of the experimental environment had no noticeable effect on the experiments and measurements. The random distribution of the residuals vs. fitted values on both sides of zero suggests that the error was randomly distributed throughout the experiments [26].

\subsection{Main effects and interaction of operating parameters}

The significance of operating parameters effects and their interactions on permeate flux using both $\mathrm{D}_{\text {on }}$ and $\mathrm{N}_{20}$ membranes are illustrated in the analysis of variance (ANOVA) in Table 2. The significance criterion (P-value) was set as 0.05 . Any change in permeate flux percentage of $\leq 0.05$ is regarded as significant, otherwise the change is regarded as insignificant. It can be noted from Tables $2 \mathrm{a}$ and $2 \mathrm{~b}$ that all operating parameters and their interactions had a significant effect on permeate flux percentage except for flow $\times$ concentration and flow $\times$ concentration $\times$ temperature using $\mathrm{N}_{20}$ which was found to be insignificant. All parameters and their 2-way interactions of feed temperature $\times$ feed flow and feed temperature $\times$ fluoride concentration had very significant effects $(P$-value $=0.000)$, and also the 2-way interaction of feed flow $\times$ fluoride concentration and the 3-way interaction of feed temperature $\times$ feed flow $\times$ fluoride concentration were significant at P-values of 0.000 .

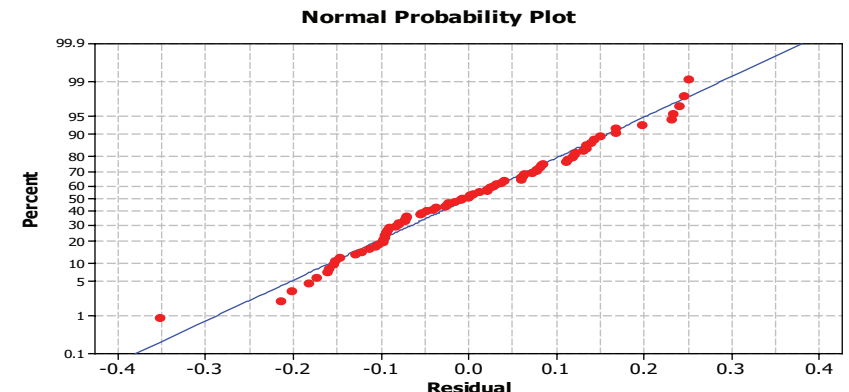

(a)

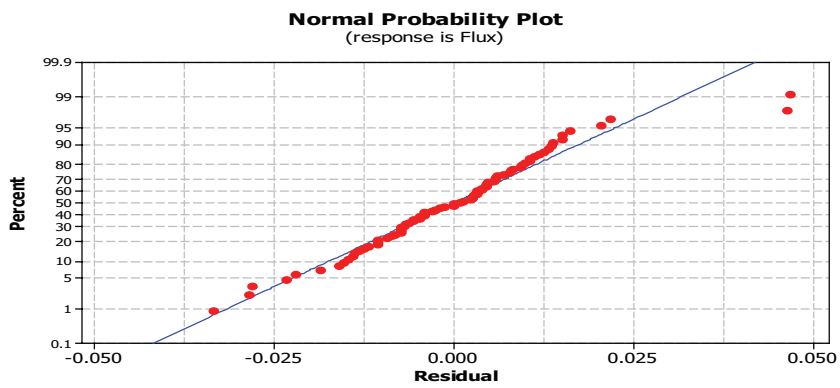

(b)

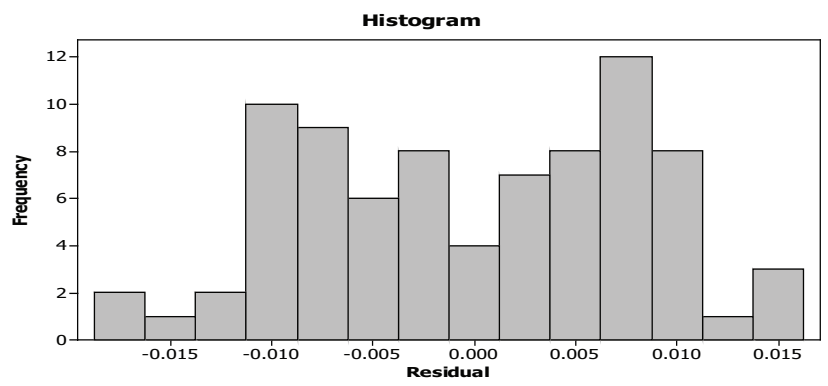

(c)

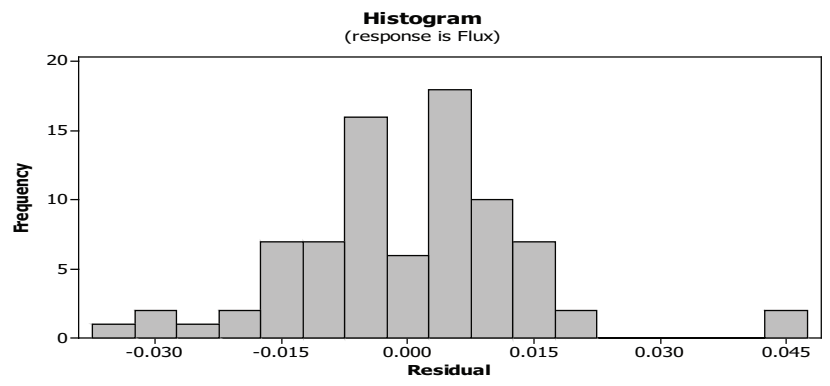

(d)

Fig. 6. Normality test figures; (a) and (b) normal probability plot and (c) and (d) residual vs. frequency plot for $\mathrm{D}_{\mathrm{on}}$ and $\mathrm{N}_{20}$ membranes, respectively. 


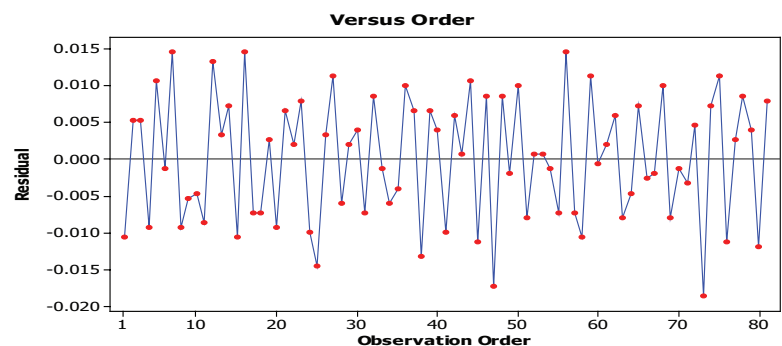

(A)

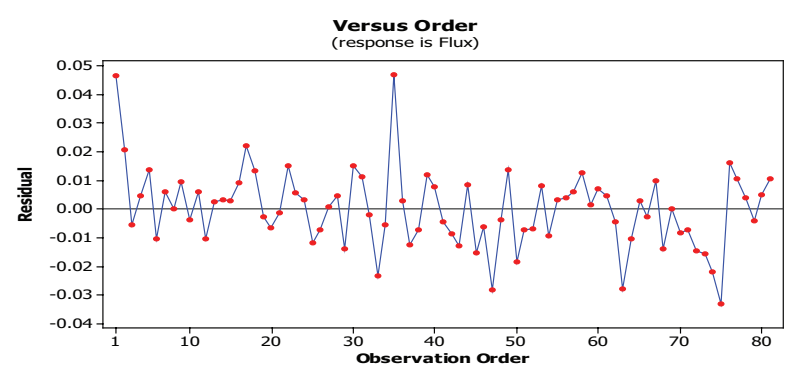

(B)

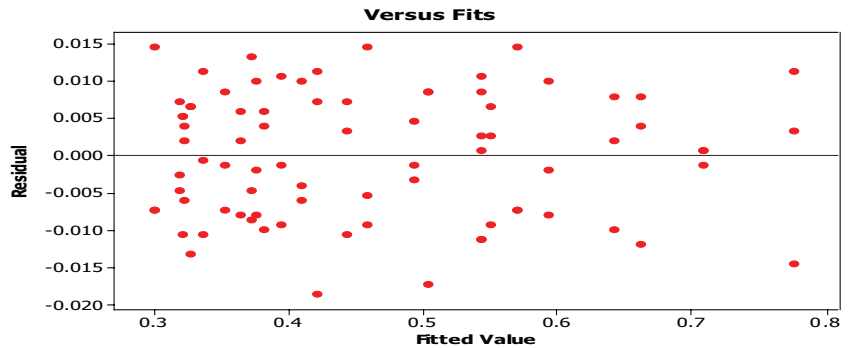

(C)

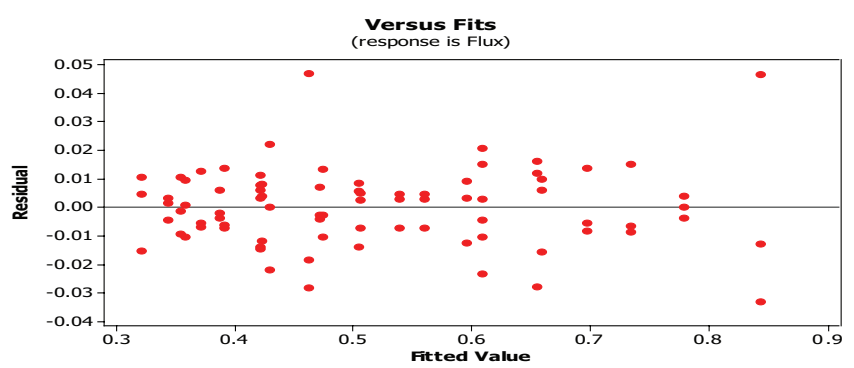

(D)

Fig. 7. Residual distribution vs; (a) and (b) observation order, and (c) and (d) fitted values for $\mathrm{D}_{\text {on }}$ and $\mathrm{N}_{20}$ membranes, respectively.

Table 2

(a) Analysis of variance for flux, using adjusted SS for tests using $\mathrm{D}_{\text {on }}$ membrane

\begin{tabular}{|c|c|c|c|c|c|c|}
\hline Source & DF & Seq SS & Adj SS & Adj MS & $\mathrm{F}$ & $\mathrm{P}$ \\
\hline $\mathrm{T}$ & 2 & 0.827723 & 0.827723 & 0.413862 & 3995.93 & 0.000 \\
\hline F & 2 & 0.406799 & 0.406799 & 0.203399 & 1963.87 & 0.000 \\
\hline $\mathrm{C}$ & 2 & 0.085708 & 0.085708 & 0.042854 & 413.77 & 0.000 \\
\hline $\mathrm{T}^{*} \mathrm{~F}$ & 4 & 0.045240 & 0.045240 & 0.011310 & 109.20 & 0.000 \\
\hline $\mathrm{T}^{*} \mathrm{C}$ & 4 & 0.009023 & 0.009023 & 0.002256 & 21.78 & 0.000 \\
\hline $\mathrm{F}^{* \mathrm{C}}$ & 4 & 0.002736 & 0.002736 & 0.000684 & 6.61 & 0.000 \\
\hline $\mathrm{T}^{*} \mathrm{~F}^{*} \mathrm{C}$ & 8 & 0.005400 & 0.005400 & 0.000675 & 6.52 & 0.000 \\
\hline Error & 54 & 0.005593 & 0.005593 & 0.000104 & & \\
\hline Total & 80 & 1.388222 & & & & \\
\hline
\end{tabular}

(b) Analysis of variance for flux, using adjusted SS for tests using $\mathrm{N}_{20}$ membrane

\begin{tabular}{lllllll}
\hline Source & $\mathrm{DF}$ & Seq SS & Adj SS & Adj MS & F & P \\
$\mathrm{F}$ & 2 & 0.503095 & 0.503095 & 0.251548 & 921.72 & 0.000 \\
$\mathrm{~T}$ & 2 & 0.936674 & 0.936674 & 0.468337 & 1716.07 & 0.000 \\
$\mathrm{C}$ & 2 & 0.119787 & 0.119787 & 0.059893 & 219.46 & 0.000 \\
$\mathrm{~F} * \mathrm{~T}$ & 4 & 0.040242 & 0.040242 & 0.010061 & 36.86 & 0.000 \\
$\mathrm{~F}^{*} \mathrm{C}$ & 4 & 0.000918 & 0.000918 & 0.000230 & 0.84 & 0.505 \\
$\mathrm{~T} * \mathrm{C}$ & 4 & 0.005627 & 0.005627 & 0.001407 & 5.15 & 0.001 \\
$\mathrm{~F}^{*} \mathrm{~T}{ }^{*} \mathrm{C}$ & 8 & 0.004437 & 0.004437 & 0.000555 & 2.03 & 0.060 \\
Error & 54 & 0.014737 & 0.014737 & 0.000273 & & \\
Total & 80 & 1.625518 & & & & \\
\hline
\end{tabular}

\subsection{Surface plot interpretations}

The surface contour plots were drawn by varying two factors and fixing the third. Surface plots provide a valuable tool not only for visual inspection of the response behaviour, but also for quick identification of the optimum parameters for the permeate flux [9]. The permeate flux with various pairs of experimental parameters are illustrated in Fig. 8. Generally, the figure shows that the flux pattern for both membranes is almost identical for vari- 
ous factors, such as combination concentration vs flux, where the $D_{\text {on }}$ membrane had almost a constant flux with different concentrations while the $\mathrm{N}_{20}$ membrane showed a slight descending trend with increasing concentration. The similarity in the flux pattern shown in Fig. 8 along with the results presented in Fig. 4 suggests that the material type of the membranes used in this study has insignificant effect on its overall productivity. Fig. 8a illustrates the response of permeate flux to the change of feed temperature and feed flow while keeping the feed concentration constant. The permeate flux of $\mathrm{D}_{\text {on }}$ and $\mathrm{N}_{20}$ membranes clearly increased when feed flow and feed temperature were increased. Fig. 8b illustrates the response of permeate flux to changes in feed temperature and fluoride concentration while keeping feed flow constant. The permeate flux with $\mathrm{D}_{\text {on }}$ and $\mathrm{N}_{20}$ generally increased with increasing temperature. Fig. 8c illustrates the response of permeate flux to the change of feed flow and fluoride concentration while keeping the feed temperature constant. For both membranes the permeate flux increased when the feed flow increased and decreased accordingly when the fluoride concentration increased.

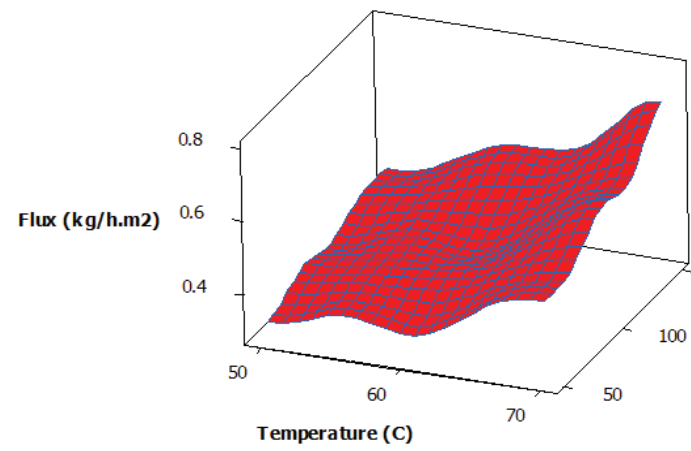

150

Flow $(\mathrm{L} / \mathrm{l}$

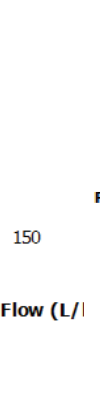

(a)
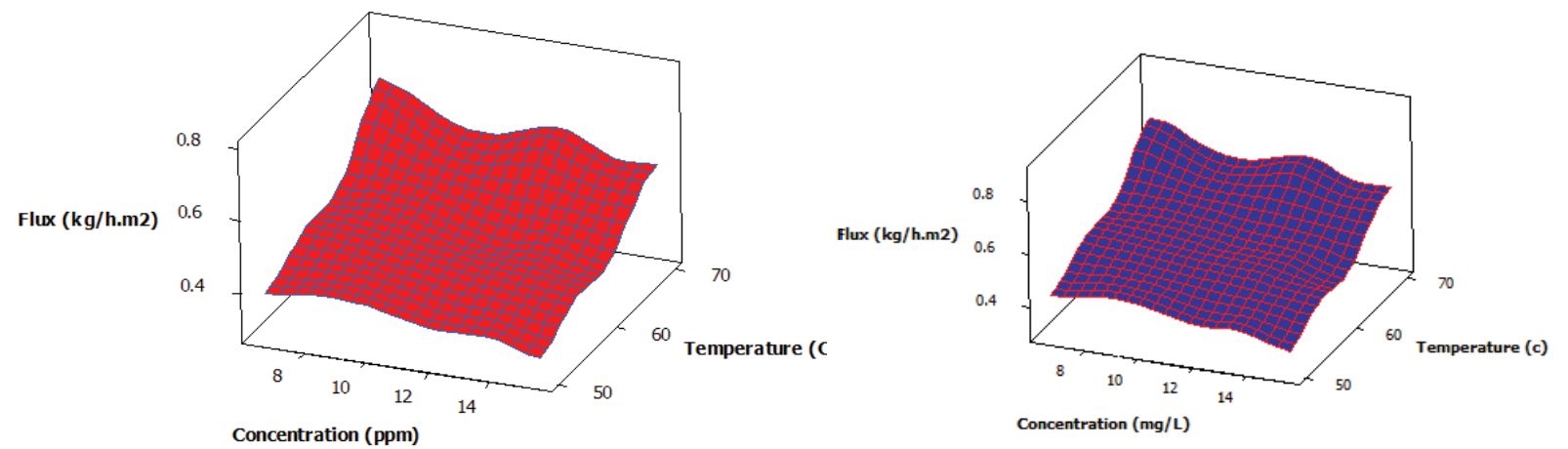

(b)
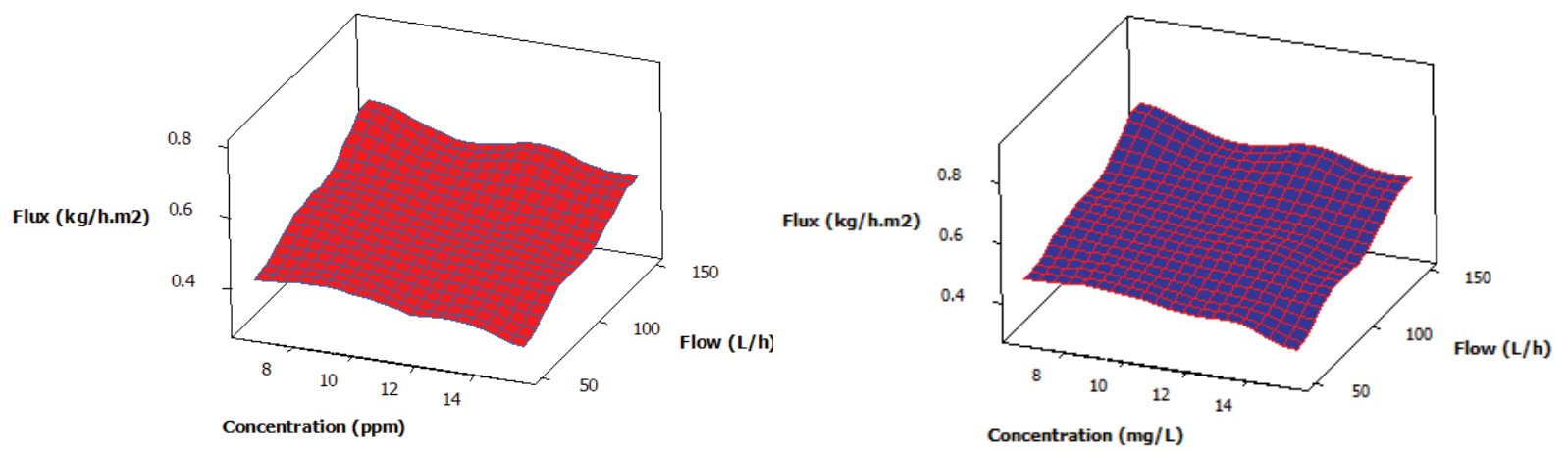

(c)

Fig. 8. Surface and contour plots of permeate flux $\left(\mathrm{kg} / \mathrm{h} \cdot \mathrm{m}^{2}\right)$ at different feed temperatures, feed flow rates and fluoride concentrations: a) feed temperature and feed flow, (b) feed temperature and fluoride concentration and (c) feed flow and fluoride concentration for both $\mathrm{D}_{\text {on }}$ (right) and $\mathrm{N}_{20}$ (left) membrane. 


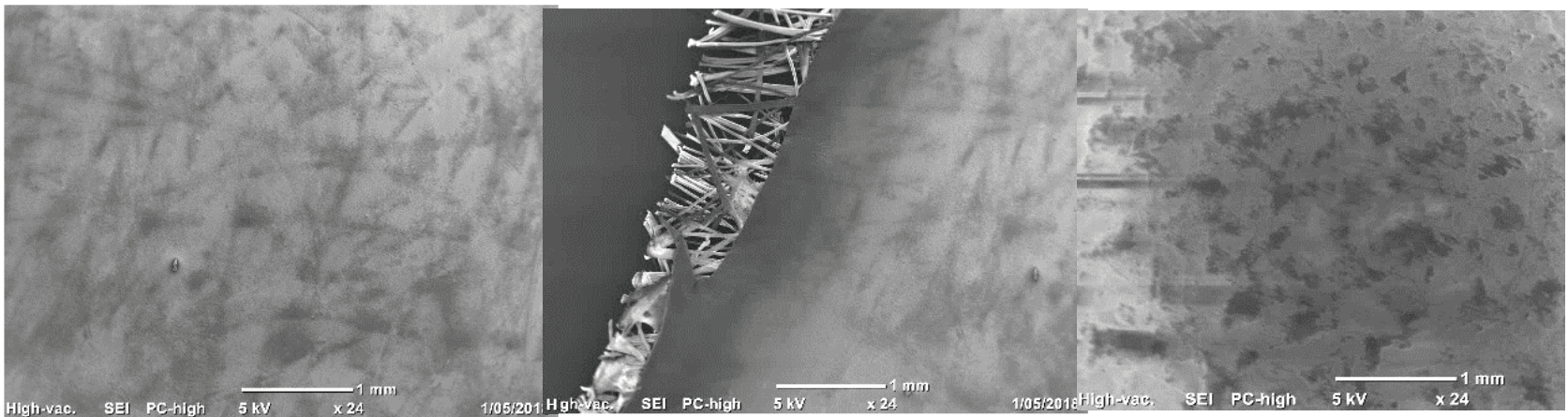

Fig. 9. SEM images of the new $\mathrm{D}_{\text {on }}$ (Left), new $\mathrm{D}_{\text {on }}$ with support layer (middle) and used $\mathrm{D}_{\text {on }}$ (right) membranes showing the fouling layer covering the membrane surface. $\left(\mathrm{N}_{20}\right.$ is not available).

\subsection{Membrane surface characterization}

The SEM pictures presented in Fig. 9 show clear signs of fouling on the membrane surface as a result of $25 \mathrm{~h}$ of fluoride removal. This fouling is likely the cause of the slight flux decay, shown in Fig. 4. A high permeate flux will inevitably create higher temperature polarization and concentration polarization [27]. The solute will then tend to precipitate on the feed side of membrane surface. In this synthetic feed solution, the percentage of solute is relatively low, thus the precipitation due to concentration polarization may be considered insignificant.

\section{Conclusions}

This study has determined and statistically validated the key factors influencing flux production in a large laboratory scale, air gap membrane distillation unit. The analysis also confirms which effects are significant and this has provided greater insight into the mechanics of the process. It was noted that flux production did not scale linearly from previous work as a result of changes in operational parameters, which have been shown to have a strong effect on flux production. The permeate flux of the two membranes having different materials was different mainly due to their different thicknesses and porosities. Fouling of the membranes was observed after approximately $25 \mathrm{~h}$ of production leading to a decrease in permeate flux but no pore wetting has been observed. Concentrations used matched those naturally found in local water sources and the fluoride contaminant removal rate was above $>98 \%$ in all experiments. Theoretical modelling of the fouling process and remedial methods of membrane cleaning are under investigation and will be reported in future works.

\section{Acknowledgements}

The research reported in this paper was supported by University of Southern Queensland, and Ministry of Higher Education and Scientific Research (Iraq). We would also like to thank our industry partners for their help and assistance. In particular, we would like to acknowledge the technical support of the Scarab Co. staff and provision of membranes from Donaldson filtration.

\section{References}

[1] World Health Organization. 2004. Fluoride in Drinking Water, WHO Guidelines for Drinking Water Quality accessed on 3 April 2005.

[2] A. Ramdani, S. Taleb, A. Benghalem, N. Ghaffour, Removal of excess fluoride ions from Saharan brackish water by adsorption on natural materials, Desalination, 250 (2010) 408-413.

[3] Meenakshi, R.C. Maheshwari, Fluoride in drinking water and its removal, J. Hazard. Mater., 137 (2006) 456-463.

[4] M.-C. Shih, An overview of arsenic removal by pressure-drivenmembrane processes, Desalination, 172 (2005) 85-97.

[5] A. Abejón, A. Garea, A. Irabien, Arsenic removal from drinking water by reverse osmosis: Minimization of costs and energy consumption, Separ. Purif. Technol., 144 (2015) 46-53.

[6] M. Piñón-Miramontes, R.G. Bautista-Margulis, A. Pérez-Hernández, Removal of arsenic and fluoride from drinking water with cake alum and a polymeric anionic flocculent, Fluoride, 36 (2003) 122-128.

[7] J.B. Gálvez, L. García-Rodríguez, I. Martín-Mateos, Seawater desalination by an innovative solar-powered membrane distillation system: the MEDESOL project, Desalination, 246 (2009) 567-576.

[8] H. Susanto, Towards practical implementations of membrane distillation, Chem. Eng. Process: Process Intensif., 50 (2011) 139-150.

[9] A. Boubakri, R. Bouchrit, A. Hafiane, S.a.-T. Bouguecha, Fluoride removal from aqueous solution by direct contact membrane distillation: theoretical and experimental studies, Environ. Sci. Pollut. Res., 21 (2014) 10493-10501.

[10] D. Hou, J. Wang, C. Zhao, B. Wang, Z. Luan, X. Sun, Fluoride removal from brackish groundwater by direct contact membrane distillation, J. Environ. Sci., 22 (2010) 1860-1867.

[11] J. Plattner, G. Naidu, T. Wintgens, S. Vigneswaran, C. Kazner, Fluoride removal from groundwater using direct contact membrane distillation (DCMD) and vacuum enhanced DCMD (VEDCMD), Sep. Purif. Technol., 180 (2017) 125-132.

[12] J. Xu, Y.B. Singh, G.L. Amy, N. Ghaffour, Effect of operating parameters and membrane characteristics on air gap membrane distillation performance for the treatment of highly saline water, J. Membr. Sci., 512 (2016) 73-82.

[13] L. Francis, N. Ghaffour, A.S. Alsaadi, S.P. Nunes, G.L. Amy, Performance evaluation of the DCMD desalination process under bench scale and large scale module operating conditions, J. Membr. Sci., 455 (2014) 103-112.

[14] A.M. Alklaibi, N. Lior, Transport analysis of air-gap membrane distillation, J. Membr. Sci., 255 (2005) 239-253.

[15] M. Gryta, Fouling in direct contact membrane distillation process, J. Membr. Sci., 325 (2008) 383-394.

[16] D.M. Warsinger, J. Swaminathan, E. Guillen-Burrieza, H.A Arafat, Scaling and fouling in membrane distillation for desalination applications: A review, Desalination, 356 (2015) 294-313. 
[17] F.A. Banat, J. Simandl, Theoretical and experimental study in membrane distillation, Desalination, 95 (1994) 39-52.

[18] L.M. Camacho, L. Dumée, J. Zhang, J.-D. Li, M. Duke, J. Gomez, S. Gray, Advances in membrane distillation for water desalination and purification applications, Water, 5 (2013) 94-196.

[19] A. Alklaibi, N. Lior, Comparative study of direct-contact and air-gap membrane distillation processes, Ind. Eng. Chem. Res., 46 (2007) 584-590.

[20] I. Minis, Supply Chain Optimization, Design, and Management: Advances and Intelligent Methods: Adv. Iintel. Mater. 2010: IGI Global.

[21] D.C. Montgomery, Design and analysis of experiments. 2017: John Wiley \& Sons.

[22] J. Antony, Design of experiments for engineers and scientists. 2014: Elsevier.

[23] D. Ranjan, P. Srivastava, M. Talatand S. Hasan, Biosorption of $\mathrm{Cr}$ (VI) from water using biomass of Aeromonas hydrophila: central composite design for optimization of process variables, Appl. Biochem. Biotechnol., 158 (2009) 524-539.
[24] T.K. Trinh, L.-S. Kang, Application of response surface method as an experimental design to optimize coagulation tests, Environ. Eng. Res., 15 (2010) 63-70.

[25] R.A. Al-Juboori, V. Aravinthan, T. Yusaf, Impact of pulsed ultrasound on bacteria reduction of natural waters, Ultrason. Sonochem., 27 (2015) 137-147.

[26] G. Venkatesan, N. Kulasekharan, V. Muthukumar, S. Iniyan, Regression analysis of a curved vane demister with Taguchi based optimization, Desalination, 370 (2015) 33-43.

[27] A.S. Alsaadi, L. Francis, G.L. Amy, N. Ghaffour, Experimental and theoretical analyses of temperature polarization effect in vacuum membrane distillation, J. Membr. Sci., 471 (2014) 138148. 